\title{
Ustilago nuda hordei
}

National Cancer Institute

\section{Source}

National Cancer Institute. Ustilago nuda hordei. NCI Thesaurus. Code C87524.

A species of smut fungi in the phylum Basidiomycota. This species causes loose smut of barley. 